\title{
Microcontroller-based Biopotential Data Acquisition Systems: Practical Design Considerations
}

\author{
José Antonio Gutiérrez Gnecchi, Daniel Lorias Espinoza and \\ Víctor Hugo Olivares Peregrino \\ Instituto Tecnológico de Morelia, Departamento de Ingeniería Electrónica \\ Morelia, Michoacán, \\ México
}

\section{Introduction}

Non-invasive bioimpedance measurements are an important part of routine diagnostic procedures. ECG (Electrocardiograph), EEG (Electroencephalograph), EMG (Electromyography) and EOG (Electrooculograph) measurements are amongst the most common non-invasive measurements used for diagnosis. The advances in microcontroller technology over the past 25 years have resulted in general-purpose, low-cost, low-power devices that can perform many of the operations involved in the measurement, and analysis process. Although the data acquisition system architecture is similar for the different noninvasive biopotential measurements, practical considerations have to be taken into account for each particular biopotential measurement: rate of amplification, filter bandpass frequency, overall bandwidth and Analogue-to-Digital conversion rate. This chapter presents an overview of the electrical characteristics of different biopotential measurements and general data acquisition architecture for portable biopotential measurement equipment. This chapter also addresses the importance of electrical isolation to ensure patient safety while using biopotential measurement equipment. Two case studies are presented: a microcontroller-based EEG data acquisition system for measurement of auditory evoked potentials for diagnosis of hypoacusis and a microcontroller-based ambulatory ECG data acquisition system.

\section{Biopotential electrical characteristics}

Non-invasive biopotential measurements rely on the fact that the activity of many body organs can be determined by measuring electrical signals in the vicinity of the organ to be studied. Amongst the most common biopotential measurements used for routine diagnosis are ECG (Electrocardiograph), EEG (Electroencephalograph), EMG (Electromyography) and EOG (Electrooculograph) measurements.

Electrocardiography refers to the registry of cardiac activity. A set of electrodes located noninvasively in the patient's thorax and extremities are used to capture small electrical signals resulting from the origin and propagation of electrical potentials through the cardiac tissues. 
Thus, it is considered that the resulting signal record called electrocardiogram (ECG or EKG) represents cardiac physiology and is used for diagnostic of cardiopathies (Kilgfield et al., 2007; Berbari, 2000). Then, a thorough analysis of electrocardiogram patterns and cardiac frequency is used for evaluating the nature of hearth disease and detecting cardiac arrhythmias.

Electroencefalogram (EEG) signals reflect vital brain activities from fetus (Preissl, 2004) and newborns (Vanhatalo \& Kaila, 2006), to adults (Cummins et al, 2007) in health and illness. In fact the EEG dynamics impact all levels of human life and their relationship with visual, auditory and somatosensory stimuli are of great importance (Klimesh et al., 2007). Brain activity is measured in a non-invasive manner by placing electrodes on the patient's scalp (Luck, 2005; Handy, 2004); the resulting data is known as encephalogram (Schaul, 1998).

Electromyography (EMG) refers to the registration and interpretation of the muscle action potentials. Electrical signals travel back and forth between the muscles and the peripheral and central nervous system control the movement and position of limbs (Hennenberg, 2000). Unlike ECG signals whose morphology and rhythm can be related to normal or abnormal cardiac activity, surface electromyography signals normally show random waveforms, because they represent a sum of action potentials from many independently activated motor units (Masuda et al, 1999). However, since the maximum frequency of EMG signals is within a couple of kilohertz, current analogue front-end instrumentation and microcontroller technologies can register muscle activity so that either time or frequency analysis methods can be used for neuromotor disorder diagnosis, functional electrical stimulation (FES) and rehabilitation.

Electrooculography (EOG) uses surface electrodes located around the eye cavity to measure potentials caused by change of illumination and/or movement of the eye. The retinal pigmented epithelium (RPE) is an electrically polarised pigmented epithelial monolayer that lies posterior to the photoreceptors and is responsible for the corneo-fundal standing potential (Arden \& Constable, 2006). Thus EOG applications range from ophthalmologic analysis, diagnosis of pathology of retinal and RPE degenerations to brain-computer interfacing (Firoozabadi et al., 2008)

\begin{tabular}{|l|c|c|c|c|}
\hline \multicolumn{1}{|c|}{$\begin{array}{c}\text { BIOPOTENTIAL } \\
\text { MEASUREMENT }\end{array}$} & $\begin{array}{c}\text { VOLTAGE } \\
\text { RANGE }\end{array}$ & $\begin{array}{c}\text { FREQUENCY } \\
\text { RANGE (Hz) }\end{array}$ & $\begin{array}{c}\text { VOLTAGE } \\
\text { RANGE }\end{array}$ & $\begin{array}{c}\text { FREQUENCY } \\
\text { RANGE (Hz) }\end{array}$ \\
\cline { 2 - 5 } & \multicolumn{2}{|c|}{ Enderle J. 2000 } & \multicolumn{2}{c|}{ Cohen A. 2000 } \\
\hline ECG, EKG, skin electrodes & $0.5-4 \mathrm{mV}$ & $0.01-250$ & $1-5 \mathrm{mV}$ & $0.05-100$ \\
\hline EEG, Scalp electrodes & $5-200 \mu \mathrm{V}$ & DC-150 & $2-100 \mu \mathrm{V}$ & $0.5-100$ \\
\hline $\begin{array}{l}\text { EMG } \\
\text { needle electrodes } \\
\text { surface electrodes }\end{array}$ & $\begin{array}{c}0.1-5 \mathrm{mV} \\
\text { EOG, skin electrodes }\end{array}$ & $\begin{array}{c}\text { DC-10,000 } \\
100 \mu \mathrm{V}-10 \mathrm{mV}\end{array}$ & $\begin{array}{c}5-10,000 \\
2-500\end{array}$ \\
\hline
\end{tabular}

Table 1. Magnitude and frequency ranges of biopotential measurements as suggested by different authors.

Although different authors suggest different amplitudes and frequency ranges (Table 1) biopotential measurements share some common characteristics. First the potential magnitude is very small (from $\mu$ Volts to miliVolts). Second, the frequency range of biopotential measurements is within a few hundred hertz to a few of Kilohertz. 


\section{General data acquisition system for biopotential measurements}

Figure 1 shows a schematic diagram of a microcontroller-based, portable, battery operated biopotential measurement system.

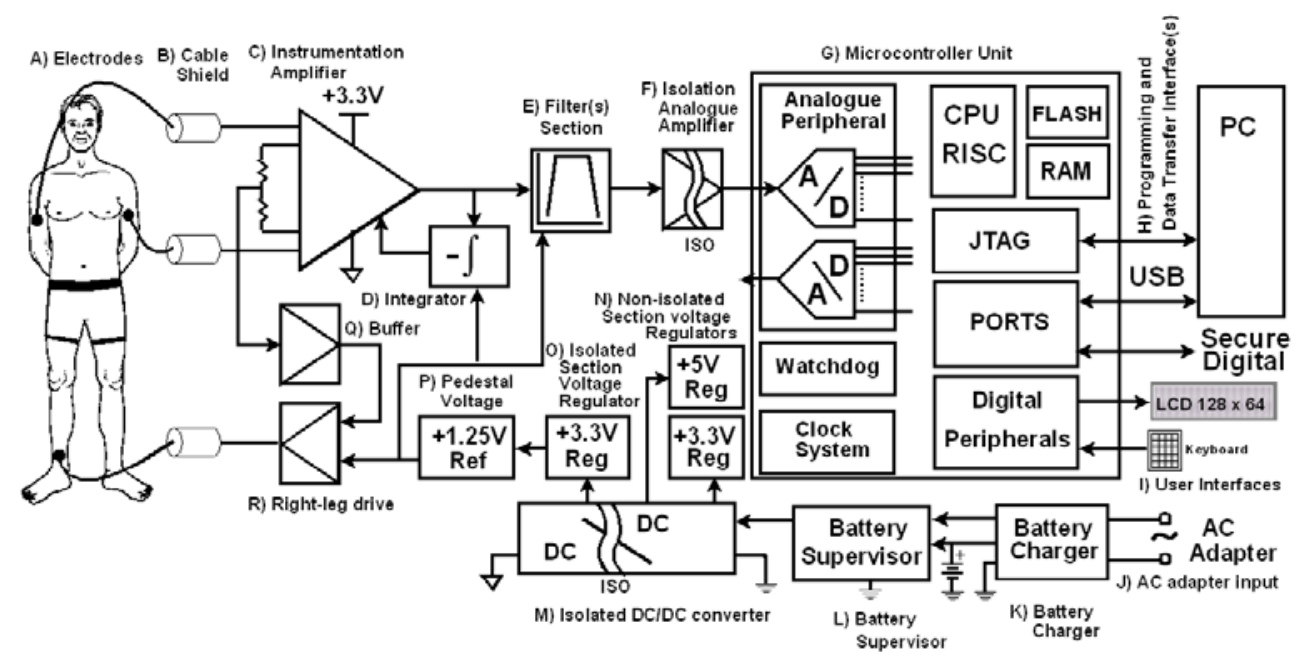

Fig. 1. Schematic diagram of a microcontroller-based portable biopotential data acquisition system (connections for ECG measurements).

\subsection{Analog signal conditioning.}

The manner in which a transducer interrogates the process, and the quality of information obtained, have a profound effect on the reliability and accuracy of the complete measurement system. Non-invasive measurement of bioelectrical signals is achieved by placing a set of surface electrodes on the skin (Figure 1A). Ionic charge carriers interact with the electrodes which serve as transducers, producing a current through the wires going into the instrumentation amplifier. A variety of electrodes exist for each particular biopotential measurement. For instance, the silver/silver-chloride $(\mathrm{Ag} / \mathrm{AgCl})$ electrode is a common choice for ECG measurements. For EEG measurements miniature gold cups of $\mathrm{Ag} / \mathrm{AgCl}$ cups are commonly used. To reduce electromagnetic interference (EMI) the cable has to be shielded (Figure 1B). To increase the effectiveness against EMI, active shielding can be used, although it requires extra operational amplifiers and a few passive components to drive the shield. The de facto analogue circuit configuration for biopotential measurements uses an instrumentation amplifier as the first signal conditioning stage (Figure 1C). To reduce the effects of EMI, an instrumentation amplifier with CMRR (Common Mode Rejection Ratio) better than $100 \mathrm{~dB}$ must be used. The electrochemical cell produced by placing the electrode in contact with the skin results in a half-cell potential. For instance for a $\mathrm{Ag} / \mathrm{AgCl}$ electrode in conjunction with the electrode gel used in ECG measurement, a $300 \mathrm{mV}$ DC is produced that is also amplified by the instrumentation amplifier. DC offset correction can be accomplished by using an integrator circuit (Figure 1D) to restore the baseline potential. The resulting signal is fed to a bandpass and notch filter to reduce the EMI caused by the mains. The common-mode is comprised mainly of two parts: 50 or $60 \mathrm{~Hz}$ interference and DC electrode offset potential. Changes in the electrode surface contact due to patient movement 
and other bioelectric signals such as EMG also contribute to measurement interference. Some of the noise is cancelled by the high CMRR of the instrumentation amplifier. Further CMRR noise rejection is achieved by deriving common-mode voltage to invert the commonmode signal and drive it back into the patient through the right leg using amplifier (right leg drive, Figures $1 \mathrm{Q}$ and $1 \mathrm{R})$.

\subsection{Patient safety considerations}

It is worrying that there is a wide availability of biopotential measurement circuits over the internet that do not consider proper isolation. Many proposed circuits and/or project reports show that the user disregarded patient safety completely. In many cases, laboratory reports show the use of common power supplies and oscilloscopes connected directly to the mains. Other documents suggest the use of commercial data acquisition systems; although some consider the use of a portable computer, at some point it may be connected to the mains through the mains adaptor creating a serious risk condition. Connecting any type of device to the body at the same time as to the mains increases the risk of electric shock. If the designer of biopotential signal conditioning systems intends to connect the equipment to the mains and/or to the PC for on-line data transferring it is his/her responsibility to ensure that the leakage currents under the worst possible scenarios are within safety limits. The IEC 60601-1-1:2005 specifies the safety guidelines medical equipment and the manner in which testing should be conducted. In particular section 8.7 of the IEC 60601-1-1:2005 deals with leakage currents and patient auxiliary currents which limit the maximum leakage current to $10 \mu \mathrm{Amps}$ for ground intact tests and $50 \mu \mathrm{Amps}$ for ground fault tests. Similar guidelines are described in the FNPA 99 Standard for Health Care Facilities and the reader is advised to refer to those documents before testing the equipment on patients. There are various ways to isolate the circuitry connected to the patient from the mains. Figure $1 \mathrm{~F}$ and $1 \mathrm{M}$ show the use of analogue isolation amplifiers and isolating DC/DC converter in the signal and power trajectories respectively. Alternatively, the isolation can be accomplished by using an optocoupler in the PC interface, although the power line has also to be isolated. The isolation amplifier can also be used for zero and span adjustment so that the measured signal occupies the entire analogue-to-digital (AD) input range.

\subsection{Digitizing section}

Current microcontrollers are powerful devices that can perform many of the operations necessary for data acquisition, signal processing, storage, display and transfer to a host computer. The analogue signal is fed to the microcontroller through the analogue-to digital converter (Figure 1G). Although a more powerful device such as a DSP (Digital Signal Processor) can perform faster and more complex calculations than a microcontroller, the frequency range of biopotential measurement (from DC to a few kilohertz) allows the execution of basic signal processing algorithms on-line and in real-time. For instance of FIR and IIR filter calculations, signal averaging and beat detection algorithms can be performed in between samples. More complex calculations such as arrhythmia detection using artificial intelligence methods and frequency-domain analysis would require a more powerful device. However, current microcontrollers are capable of interfacing with the user for operating the device (Figure 1I), transferring the data to a host PC for further analysis and allow in-system programming (Figure $1 \mathrm{H}$ ) so that the equipment can be updated without altering the circuitry. 


\subsection{Power supply}

Although portable measurement equipment can be effectively isolated by avoiding the use of an external AC adaptor and linking wirelessly to the host PC, the proposed scheme uses a battery charger to power up the device when the battery is depleted (Figure 1J and 1K). A battery supervisor selects the power source and feeds the isolating DC/DC converter to provide power to both sections of the circuit (Figure 1M). Two low dropout regulators provide the voltage for the digitizing and signal conditioning sections (Figure $1 \mathrm{~N}$ and 1O). Since the analogue circuitry is powered by a unipolar voltage signal, the pedestal reference voltage is obtained from a voltage reference circuit with temperature variation coefficient better than $100 \mathrm{ppm} /{ }^{\circ} \mathrm{C}$. Alternatively a rail splitter circuit can be used. Thus bipolar input signals are measured using unipolar circuit polarization voltage. The non-isolated section uses two voltage regulators: $\mathrm{a}+3.3 \mathrm{~V}$ and $+5 \mathrm{~V}$. The +3.3 regulator powers up the microcontroller whereas the $+5 \mathrm{~V}$ is used for supplying power to other devices such as the SD card.

\subsection{Pre-competitive design}

The great importance that biopotential measurements have for diagnostic, have led to a continuous scientific and technological effort to produce highly integrated data acquisition systems and powerful signal processing methods for eHealth applications. The current tendency in medical informatics in developed countries is directed towards three key issues (Maglogiannis et al., 2007): the widespread availability of software applications, availability of medical information anytime-anywhere and computation transparency. A typical application is telemedicine that involves measurement of physiological parameters for transmission to a remote location where specialists can provide diagnostic in real-time over a wireless connection. There are numerous commercial equipments available. However, in developing countries, as far as public health is concerned, the current eHealth needs are different, and the differences of technological capabilities of the public sector, compared to the private sector, are huge. Therefore, one of the main goals of university research and development activities must be the direct application of the results in the surroundings to impact health care positively.

Pre-competitive design for biomedical applications in developing countries involves identifying the current needs for instrumentation and deriving the appropriate solution according to those needs. Therefore, it can be considered as a middle-ground between university state-of-the-art research and commercial research performed by large corporations and/or public health institutions. It may is also be required that a third party, interested in advancing the state's own technology to promote the continuous development of technology, contributes funding and expertise to the development process. In the following sections two pre-competitive design case studies are presented: a microcontrollerbased EEG data acquisition system for measurement of auditory evoked potentials for diagnosis of hypoacusis and a microcontroller-based ambulatory ECG data acquisition system auxiliary in the detection of cardiac arrhythmias.

\section{Case study 1: Microcontroller-based EEG auditory evoked potentials measurement system auxiliary in the diagnosis of hypoacusis.}

Although a great deal of research effort has been put into developing working Brain Machine Interfaces (BMI) (Sadja, 2008), still, development of EEG diagnostic equipment occupies an important place in research and development. Improvements and new devices are continually 
reported and registered for measuring Brain stem evoked potentials (Fadem, 2005; Kopke, 2007; Givens et al., 2005; DeCharms, 2007), as well as signal processing and analysis methods (Lam, 2007). Measurement of Event Evoked Potentials (AEP) due to external stimuli, allows the analysis of brain signal processing activities (Bonfis et al., 1988). Recent developments on signal processing and wireless technologies have also resulted in a number or commercial and experimental EEG devices. One particular application of EEG equipment is the diagnosis of hypoacusia by measuring auditory evoked potentials (AEP).

Hypoacusis (or hypocusya), refers to the level of hearing impairment of patients. One of the main factors that influence the recovery of patients suffering from hypoacusis is the early detection of auditory pathologies (National Institute of Health, 1993). For newborn patients, it is very important to obtain a diagnosis during the first three to six months after birth, so as to increase the chances of successful recovery and favor speech development. More than $90 \%$ of children suffering from moderate or acute hypoacusis are likely to go through correct hearing, intellectual and emotional development (Bielecki, 2004) if they are diagnosed during the first year after birth.

One of the reasons for continuous development of AEP measurement equipment is the noninvasive nature of the test: using a set of electrodes on the scalp, it is possible to register signals related to brain activity, in response to auditory stimuli. In addition, the objective nature of the test is suitable for screening newborns that cannot provide feedback information for diagnosis. The importance of AEP tests is recognized in Mexico's Health standard NOM-034-SSA2-2002, recommending its use for screening of hypoacusis risk cases during the first trimester after birth. However early diagnostic screening tests are not conducted regularly due to the lack of specialized equipment in public health hospitals. Thus there is little statistical information regarding hypoacusis information in Mexico. A sole study conducted in 16 states of Mexico reported that more than $20 \%$ of the population in rural areas of Michoacan, Mexico, suffer from some level of hypoacusia; $4.71 \%$ of the population suffer from moderate to severe hypoacusia (Rodriguez-Díaz et al., 2001). In rural areas in Mexico, where there is little or null access to diagnostic equipment, it is common to find patients suffering hypoacusia that are not diagnosed until much later in life precluding their integration to social and school life. There are a number of methods for diagnosis of hypoacusia; otoacoustic emission (EOAE) and impedance audiometry are amongst the most commonly used methods (White et al., 1993). Alternatively, assessing the hearing ability of patients can be achieved by measuring brain activity due to external acoustic stimuli. Thus, the use of EEG measurement equipment with Evoked Potentials analysis capabilities can be a cost-effective solution for the assessment of brain activity due to external auditory stimuli. In particular for newborn patients who can not provide feedback for diagnosis, the objective and non-invasive nature of the technique can provide useful information for early diagnosis of hypoacusia. This case study presents the design and construction of portable microcontroller EEG measurement equipment with auditory evoked potential analysis capabilities on request from the Michoacán State Public Health Secretariat (Spanish: Secretaría de Salud del Estado de Michoacán), Mexico. The aim is to produce equipment that can be used to asses the hearing capabilities of patients even if the study is carried out under non-controlled conditions (i.e noise proof facilities). Such equipment could then be used in locations where sound proof facilities are not available and a quiet room with ambient noise may suffice. The EEG equipment is initially intended for being used with a host PC for transferring the test results and keep patient records to aid statistical analysis and help establishing public health policies for the recovery of young patients. The software 
must be intuitive, provide the analysis functions commonly encountered in commercial equipment and permit registration of patient data.

\subsection{EEG-ITM04 data acquisition system}

Fig. 2 shows the schematic diagram of the EEG-ITM04 auditory evoked potential measurement system.

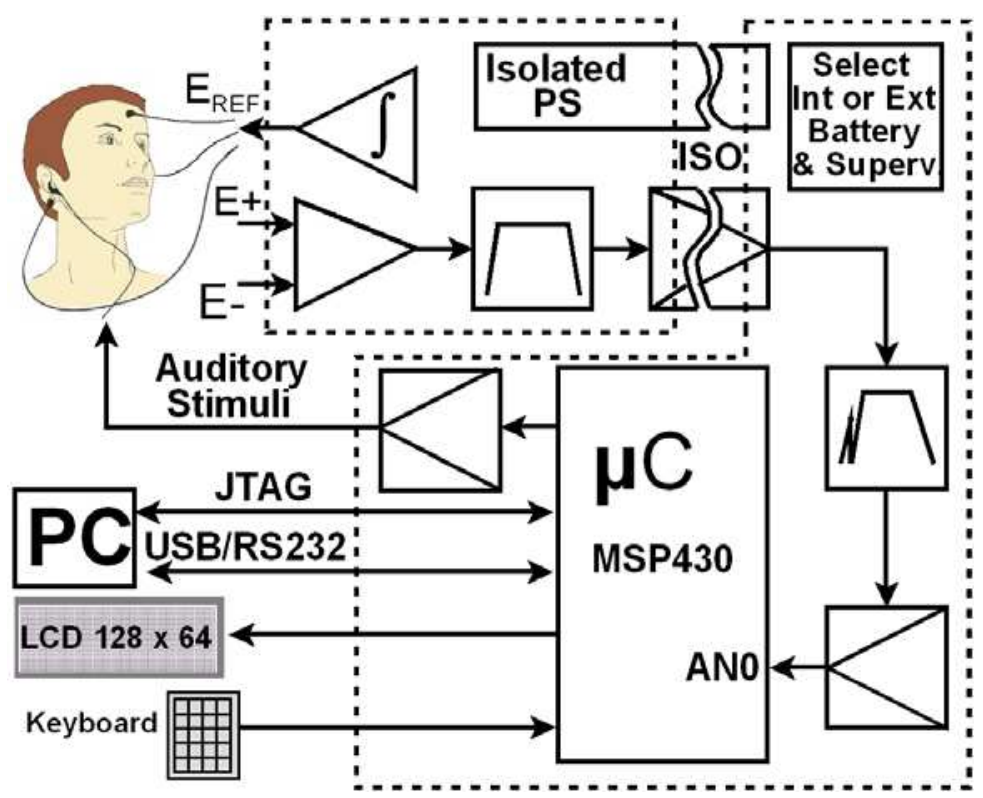

Fig. 2. Block diagram of the EEG-ITM04. A) Three-electrode scheme for measuring AEP, B) bandapass filter, C) analog isolation amplifier, D) notch and bandpass filter, E) signal scaling, F) microcontroller, G) auditory stimulus amplifier, H) user interface devices, I) power source selection and battery supervision, J) Isolated power supply.

One of the analogue to digital converter inputs of the microcontroller is used for digitizing the measured signals at a rate in excess of $40 \mathrm{KSPS}$ (kilo samples per second) (Fig. 2F). The auditory stimulus consists of a 0.2 second duration pulse, (click). The microcontroller also synchronizes the data acquisition process with the auditory stimuli (Fig. 2G). The user operates the equipment through a keyboard, and LCD display. As well as its predecessor, the EEG-ITM04 includes a JTAG port for in-system programming and RS232 for data transfer to the host computer (Fig. 2H). An RS232-USB converter cable is used to interface the device with current personal computer systems.

\subsection{Safety requirements}

Although the circuitry uses an isolated power supply and isolation amplifiers, electrical safety is of great concern since the main purpose is directed towards evaluating hearing of newborns. Before the equipment is tested on patients, measurements were taken under different single-fault and normal operating conditions. The equipment was considered safe if, at least, minimal IEC60601-1 and NFPA 99 leakage current specifications are met: 

A.- Patient to Ground (isolated): $\leq 10 \mu \mathrm{A}$ (GND intact)
B.- Patient to Ground (isolated): $\leq 50 \mu \mathrm{A}$ (GND open)
C.- Between Leads (isolated): $\leq 10 \mu \mathrm{A}$ (GND intact)
D.- Between Leads (isolated): $\leq 50 \mu \mathrm{A}$ (GND open)
E.- Between Leads (non-isolated): $\leq 50 \mu \mathrm{A}$ (GND intact or open).

The circuitry enclosure was placed on an isolated surface (rubber over wood) 3 meters away from any earthed surface. Leakage current measurement equipment was located $40 \mathrm{~cm}$ away from unscreened power cables. Measurements were carried out on all possible combinations (patient leads and AC adapter connections) using a $61 / 2$ digit meter. For ground-intact tests, the largest leakage current measured was $1.45 \mu \mathrm{A}$, between the reference electrode terminal and the mains ground. For ground-open tests the largest leakage current registered was $10.36 \mu \mathrm{A}$ between the reference electrode terminal and the mains ground. Both measurements are within the safety specification values $(10 \mu \mathrm{A}$ and $50 \mu \mathrm{A}$ respectively) and thus, pending corroboration from a certified laboratory, the equipment was considered safe.

\subsection{Acoustic stimulus}

One of the most commonly used methods for generating the auditory stimuli for auditory evoked potential tests consists of producing a sequence of pulses to drive a set of earphones, and record the resulting brain electrical activity over a period of a few milliseconds. Since the magnitude of the evoked response has a magnitude of just a few microvolts, the process is repeated 1000 to 2000 times and the results are averaged to improve the Signal-To-Noise Ratio. Assuming that the resulting data is a function, only, of the auditory stimuli, the averaged signal represents the hearing process. The data acquisition process has to be synchronized with the application of auditory stimuli, which consists of a 0.2 miliseconds pulse, which in turn drives the earphones. The pulse is generated 6.66 times per second. The output signal was calibrated using a TES1350 decibel meter, and a graduated scale is provided behind the amplitude control potentiometer in the frontal panel of the equipment.

\subsection{Measurement of auditory evoked potentials}

Auditory evoked potentials are characterized by three main parameters: polarity, latency (i. e. the moment of peak occurrence after stimulus presentation) and scalp distribution. Figure 3 shows a typical reference wave pattern for diagnosis of AEP.

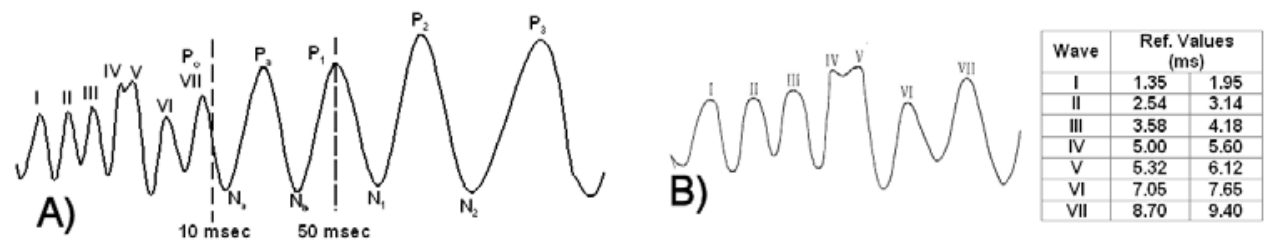

Fig. 3. A) Typical AEP showing the three components and B) diagnostic reference values extracted from a test report sheet (Courtesy of Clinica de Especialidades de Morelia).

There are three types of components: early latencies or components (up to 10 miliseconds after the stimulus has been applied), middle components (from 10 miliseconds to 50 miliseconds) and late components (after 50 miliseconds). Although measurement of 
auditory evoked potentials does not constitute a hearing test per se, it can provide information about the hearing process. In addition, evoked potentials are not influenced by the state of consciousness (i. e. patient can be asleep) and result in objective data that do not require feedback from the patient. The occurrence of waves I - VII (Figure 3B) can be indicative of hearing whereas absence of some (or all) of them may indicate a hearing impairment. To produce the AEP graph it is necessary to apply the stimulus for 1000 to 2000 epochs (i.e. application of the stimulus and subsequently measure the resulting EEG signals) (1):

$$
S_{k}=\mu+n_{k}
$$

where $S_{k}$ represents the $k^{\text {th }}$ epoch, $\mu$ is the deterministic evoked response and $n_{k}$ represents zero-mean white noise uncorrelated to $\mu$ (Ropelman \& Ros, 1986). For AEP measurements, is common to find that the early latencies (up to $10 \mathrm{~ms}$ ) are used for diagnostic. However the magnitude of the measured signals is very small, and considering that the data acquisition process is synchronized with the stimulus, a signal analysis method consists of averaging the results of each epoch to improve the Signal-To-Noise ratio (SNR). Averaging over N data sets, $\mathrm{Y}_{\mathrm{N}}$, can then be written as (2):

$$
\boldsymbol{Y}_{N}=\frac{1}{N} \sum_{k-1}^{N} \boldsymbol{S}_{k}=\mu+\frac{1}{N} \sum_{k-1}^{N} \boldsymbol{n}_{k}
$$

The advantage of this method is that it can easily be implemented on-line. The microcontroller chosen for this application is the MSP430F149IPAG from Texas Instruments. The MSP430 includes 2KB of RAM and $60 \mathrm{~KB}$ of flash memory. Each epoch begins by acquiring 2 miliseconds worth of data prior to producing the auditory stimulus; 15 miliseconds worth of data (after the stimulus is applied) are acquired by the microcontroller at a rate in excess of $40 \mathrm{KSPS}$, with 12 bit resolution. The data acquisition process results in a set of 800 12-bit values which are stored in RAM. During the following epoch, the microcontroller converts each sample and averages it with respect to the corresponding sample previously stored in RAM, replacing the old value. The process continues during the entire procedure until the test has concluded. The result is then stored in flash memory, occupying four $512 \mathrm{~kb}$ memory segments. It is common to find that additional digital filtering is required for enhancing the quality of the results. Once the test has finished and the resulting data is stored in flash memory, a digital filter, $G(z)$, given by (3) can be implemented off-line.

$$
G(z)=\frac{a_{0}+a_{1} z^{-1}+a_{2} z^{-2}+\ldots}{1+b_{1} z^{-1}+b_{2} z^{-2}+\ldots}
$$

The state variable description of the filter (4):

$$
\begin{aligned}
& {\left[\begin{array}{l}
x_{1}(k+1) \\
x_{2}(k+2)
\end{array}\right]=\left[\begin{array}{cc}
0 & 1 \\
-b_{1} & -b_{2}
\end{array}\right]\left[\begin{array}{l}
x_{1}(k) \\
x_{2}(k)
\end{array}\right]+\left[\begin{array}{l}
0 \\
1
\end{array}\right] e(k)} \\
& u(k)=\left[\begin{array}{ll}
a_{1} & a_{0}
\end{array}\right]\left[\begin{array}{l}
x_{1}(x) \\
x_{2}(k)
\end{array}\right]
\end{aligned}
$$


can be implemented easily in canonical form as a subroutine of the microcontroller program (Figure 4). (Gutiérrez-Gnecchi, 2009).

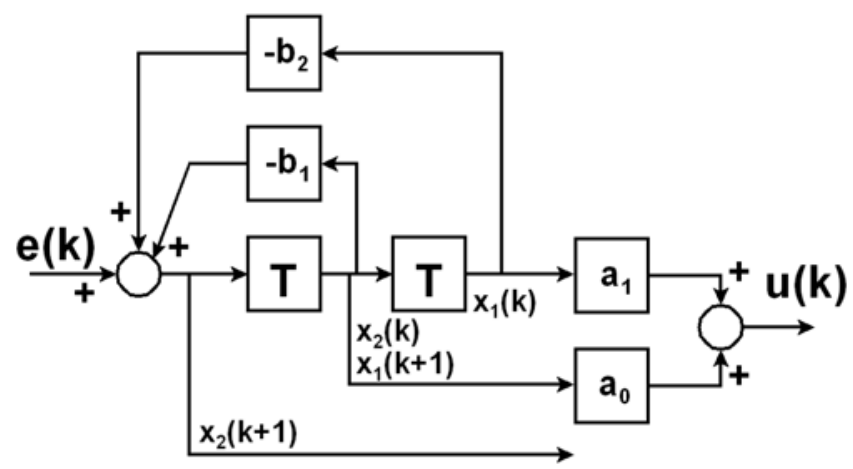

Fig. 4. Digital filter implementation

\subsection{Software}

A program, written in $\mathrm{C}++$, was developed for transferring the test results to a host PC The program permits to register patient and test information (patient data, type of test, etc.). The program also shows on-line EEG data. Once the test has been completed, the program receives the data from the microcontroller. The EEG data can then be stored, plotted and subjected to further filtering and analysis. The program consists of three main windows. The first window registers the test and patient data (Figure 5A). The second window (Figure 5B) can be accessed by selecting the "CALIBRATE" button. Selecting the "GO ON-LINE" button displays on-line EEG data for the purpose of offset and gain adjustment of the measured signal. Activating the "GO TO TEST" initiates the test. The third window shows the test results (Figure 5C).

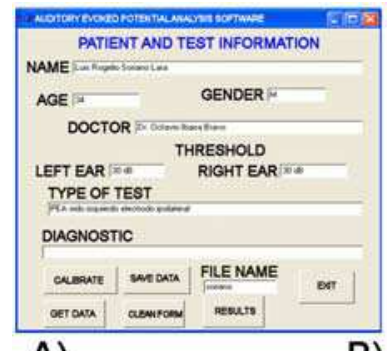

A)
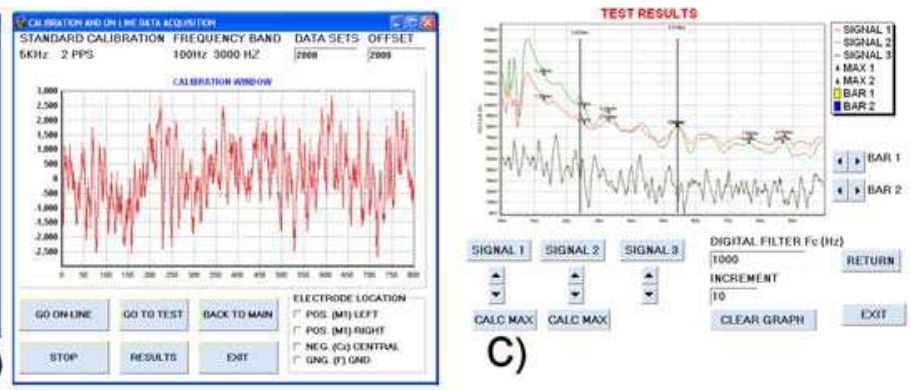

C)

Fig. 5. A) Screen of the window first program used for registering patient information, B) calibration window and C) test results window. Results are shown for a healthy 34-years old male patient. The latencies are detected in agreement with expected values for healthy patients. C) 
The test results window can display the results for both ears. In addition, to help the identification of the latencies (i.e. when the evoked potentials occur), there are buttons for calculating the local maximum values for both signals. A third unprocessed signal can be displayed for comparison. Additionally to the averaging function, a low-pass filter can be applied to the resulting evoked potential results. Horizontal displacement bars allow the exact identification of the time when the latencies occur.

\subsection{Validation of the EEG-ITM04}

Figure 6A shows the assembled EEG-ITM04.
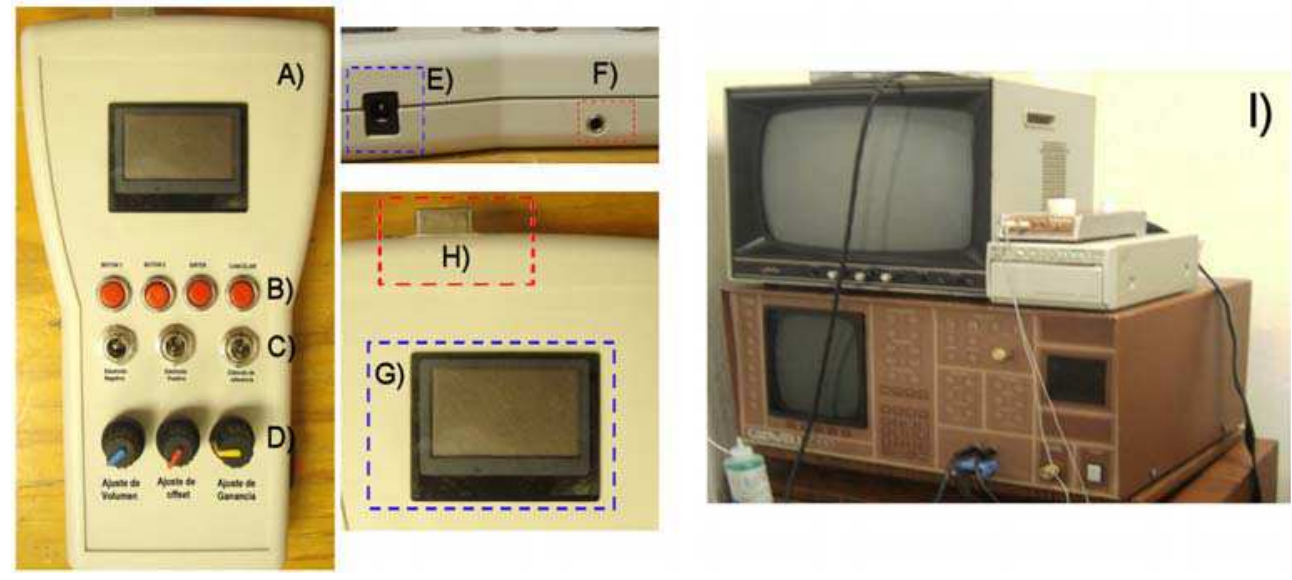

Fig. 6. The assembled EEG-IMT04 is a A) handheld device which includes B) menu navigation buttons, C) electrode connections, D) EEG signal adjustment knobs, E) AC adaptor connector, F) earphone plug connector, G) a 128 X 64 LCD and H) computer interface connector. I) Cadwell 7200 electroneurodiagnostic equipment.

In order to validate the performance the EEG-ITM04, a series of experiments were conducted at the Clinica De Especialidades de Morelia. Commercial equipment (CADWELL 7200, Figure 6I) was used for obtaining reference information. The EEG signals are measured using a three-electrode scheme. The positive and negative electrodes are connected over the ipsilateral (Figure 7A) and contralateral (Figure 7B) to the mastoid processes respectively. The reference electrode is located in the middle of the forehead (Figure 7C). The tests were conducted on 10 unmedicated young adults (average age of 25 years old. The test procedure was conducted in a quiet room, with the patients lying down, eyes closed, to avoid registering data from other types of sensory stimulation. Figure 8 shows the experimental set-up and the results of using the Cadwell 7200 and EEG-ITM04 on Patient 1. 

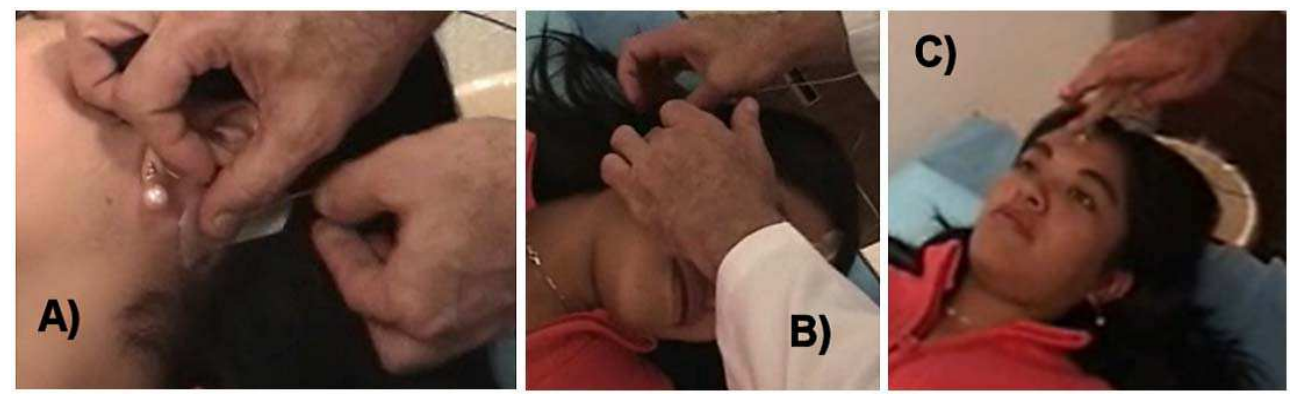

Fig. 7. Location of the electrodes for AEP measurements (testing the left ear). The positive and negative electrodes are connected A) ipsilateral and B) contralateral to the mastoid process. C) The reference electrode is located in the middle of the forehead.
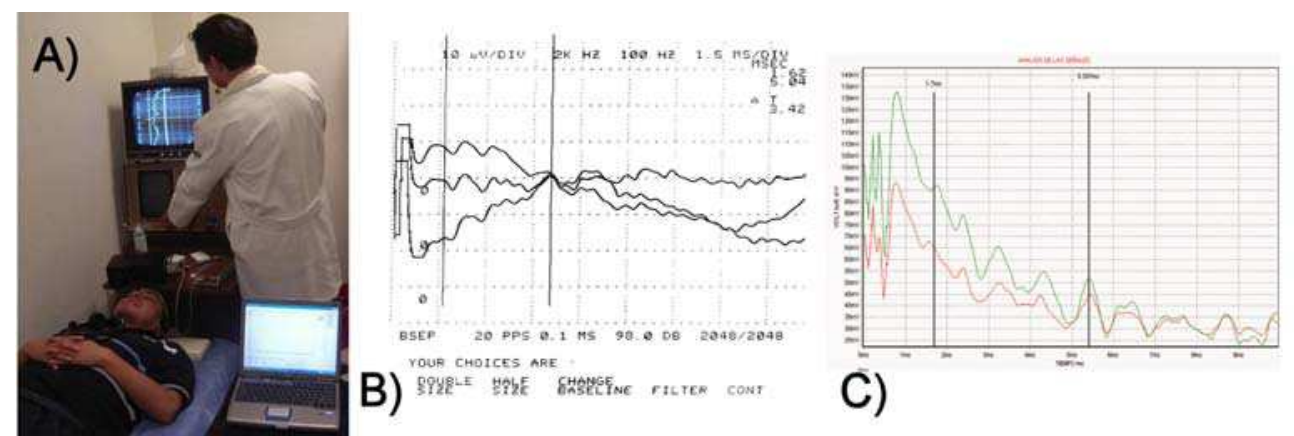

Fig. 8. A) Experimental set-up. Test results obtained for patient 1 using B) the Cadwell 7200 and C) EEG-ITM04.

In order to validate the performance of the EEG-ITM04, a series of tests using a $95 \mathrm{~dB}$ acoustic stimulus, at a rate of 6 pulses per second for 2048 epochs, were carried out using the Cadwell 7200 Electro-neurodiagnostic instrument (Figure 6I) for obtaining reference information (Figure 7B). Similar tests were conducted using the EEG-ITM04, using a $95 \mathrm{~dB}$ acoustic stimulus, at a rate of 6.66 pulses per second for 2048 epochs (Figure 7C).

\subsection{Results and discussion}

Table 2 shows a summary of the results for the 10 patients tested. The results show agreement between the CADWELL 7200 and EEG-ITM04 equipments, thus suggesting that the EEG-ITM04 can be used for diagnostic of some forms of hypoacusia, in non-ideal environments. Undoubtedly, there will be differences in the results between the CADWELL and EGG-ITM04. Different specifications for both devices and testing under slightly different conditions result in the differences shown. However, the results indicate that it is possible to detect the auditory evoked potentials even if the test is conducted on a non-ideal environment. 


\begin{tabular}{|c|c|c|c|c|c|c|c|c|c|c|}
\cline { 2 - 11 } \multicolumn{1}{c|}{} & \multicolumn{3}{c|}{$\begin{array}{c}\text { CADWELL 7200 } \\
\text { Latencies (miliseconds) }\end{array}$} & \multicolumn{5}{c|}{ LEG-ITM04 } \\
\cline { 2 - 11 } & I & II & III & IV & V & I & II & III & IV & V \\
\hline Patient & 1.62 & & & & 5.04 & 1.720 & & & & 5.390 \\
\hline $\mathbf{1}$ & & & 3.64 & & 5.56 & & & 3.528 & & 5.631 \\
\hline $\mathbf{2}$ & & & 3.68 & & 5.44 & & & 3.571 & & 5.652 \\
\hline $\mathbf{3}$ & 1.44 & 2.88 & & & & 1.445 & 3.121 & & & \\
\hline $\mathbf{4}$ & & 2.72 & & & 5.36 & & 2.763 & & & 5.785 \\
\hline $\mathbf{5}$ & & & 3.52 & & 5.39 & & & 3.560 & & 5.515 \\
\hline $\mathbf{6}$ & 1.59 & & & & 5.19 & 1.635 & & & & 5.253 \\
\hline $\mathbf{7}$ & & 2.75 & & & 5.37 & & 2.810 & & & 5.471 \\
\hline $\mathbf{8}$ & 1.56 & 2.77 & & & & 1.550 & 2.781 & & & \\
\hline $\mathbf{9}$ & & & 3.69 & & 5.58 & & & 3.692 & & 5.921 \\
\hline $\mathbf{1 0}$ & 1.49 & & & & 5.16 & 1.510 & & & & 5.180 \\
\hline
\end{tabular}

Table 2. Summary of test results obtained from 10 patients using the Cadwell 7200 and EEGITM04 equipments

\section{Case study 2: microcontroller-based ambulatory ECG data acquisition system auxiliary in the detection of cardiac arrhythmias.}

Cardiovascular disease is of on the main causes of morbidity and mortality in Mexico (Velazquez-Monroy et al., 2007) and worldwide (Abegunde et al., 2007). The epidemic importance of chronic non-communicable diseases (CNCD) spread is currently overtaking infectious and parasitic diseases. In particular in emerging economy countries the rate of CNCD spread is greater than that in developed countries. In México ischemic hearth disease is the main cause of death and $15 \%$ to $30 \%$ of patients that have suffered an acute cardiac adverse event will die within the next 30 days (INEGI, 2002). In addition, current life habits such as sedentary life style, sodium, alcohol and tobacco consumption and poor diet habits increase the chances of suffering hearth disease early in life (Myers, 2003). Therefore, early arrhythmia detection by means of an electrocardiogram is a key factor in preventive treatment. A standard ECG uses 12 derivations or measurements of electric potential in different areas of the patient's body. A normal ECG consists of a repeated sequence of $P, Q$, $\mathrm{R}, \mathrm{S}$ and $\mathrm{T}$ waves (Figure 9). The characteristics of a normal ECG sequence have been studied for over a century, and a set of normal conditions, usually described as a regular sinus rhythm (Ivanov, 2007), have been established for diagnostic purposes. When the rhythm, frequency or morphology of the ECG signal corresponding to the heartbeat sequence, are not consistent with those of the normal ECG, the condition is called arrhythmia. In general is considered that over $90 \%$ of arrhythmias can be detected by using a 3-derivation ECG (Figure 1B). 

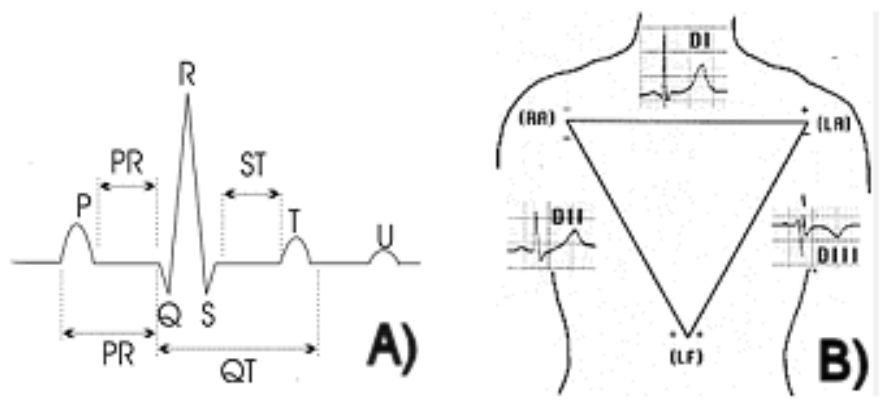

Fig. 9. A) Electric cardiac cycle and B) Three bipolar derivations (Einthoven Triangle)

There are two basic types of ECG monitors: continuous and intermittent recorders. Continuous ambulatory and recorders, also known as ambulatory electrocardiogram, ambulatory EKG, Holter monitoring, 24, 48, 72-hour EKG, or cardiac event monitoring continuously register on internal or external memory the cardiac activity. Intermittent recorders, either loop or event recorders, store data on request, generally by pressing a button. Since many cardiac events occur randomly and for a short period of time, it is desirable to store the ECG data continuously during the study.

The great importance that electrocardiography measurements have for diagnostic, have led to a continuous scientific and technological effort to produce signal processing methods for arrhythmia classification and ECG equipment. There are numerous commercial equipments and specialized software for arrhythmia detection. Although the advances in electronics have permitted that desktop or wearable ECG measurement systems are available for $\$ 1000$ and $\$ 4000$ UsDlls respectively, the added taxes and import costs result prohibitive for wide distribution in public health clinics in Mexico. Budget restrictions and the vast amount of patients and their medications impede the purchase of monitoring equipment and cardiac patients are referred to private clinics for biopotential measurements. Therefore it is necessary to dedicate research and development efforts in accordance with the current regional needs. The work presented in this case study is the result of a cooperation agreement between Morelia Institute of Technology and the Michoacán State Public Health Secretariat, financially supported by the Public Education Secretariat (SEP-DGEST) to develop royalty-free biomedical instrumentation equipment that facilitates routine diagnostic activities. The equipment ECG-ITM04 must have a number of specific characteristics. First the equipment must be able to allow ECG monitoring during routine diagnostic and during ambulatory activities for a period of 7 days. The instrument has to show on-line the ECG signals. The ECG-ITM04 has to be able to transfer the information online to a host computer during routine diagnostic. In case that the battery fades, a portable power supply has to be used to power up the device and charge the battery, while ensuring the safety of the patient. Finally it must be possible to upgrade the software to include further signal processing algorithms for arrhythmia detection and classification. 


\subsection{Hardware design}

The schematic diagram of the ECG-IMT04 is actually shown in Figure 1. The equipment consists of 4 main sections: isolated power supply, analog signal conditioning and filtering, digitizing and signal processing, and data display and storage.

\subsection{Isolated power supply}

Since the ECG-ITM04 is intended for ambulatory measurements as well as for on-line transfer of ECG data to a host PC, it is essential to ensure patient safety from exposure to leakage currents. There are 3 main conditions of risk when operating the ECG: when the equipment is connected to the AC adapter, when the equipment is connected to the host $\mathrm{PC}$ or both. The power supply circuitry (Figure 1J - 1M) consists of an external input for a 9 Volt AC adapter, an RF input filter, a Nickel-Metal Hydride battery charger and supervisor, a 3$\mathrm{kV}$ isolated DC-DC converter and two low dropout regulators ( $3.3 \mathrm{~V}$ and $5 \mathrm{~V})$. Thus, the section dedicated for analog signal conditioning and filtering is effectively isolated from the digitizing section.

\subsection{Analog signal conditioning}

Measurement of cardiac signals is carried out by using a 3-wire scheme using a 110 $\mathrm{dB} C \mathrm{CMMR}$ instrumentation amplifier, right-leg drive signal, high- and low pass filters to provide a $200 \mathrm{~Hz}$ measurement bandwidth $(0.02-200 \mathrm{~Hz}$ ), and gain adjustment (Figure 2E).

\subsection{Digitizing and signal processing}

The ECG_ITM04 is based on the MSP430F149 IPAG microcontroller from Texas Instruments $\odot$. The MSP430 is a 16-bit RISC, ultralow-power device with five power-saving modes, two built-in 16-bit timers, a fast 12-bit A/D converter, two universal serial synchronous/asynchronous communication interfaces (USART), 48 Input/Output pins, 60 $\mathrm{kB}$ of flash memory and $2 \mathrm{kB}$ of RAM, which permits the implementation of all the functions required to build an ECG data acquisition system. Initially, it was considered that basic signal processing algorithms (digital filter and beat detection) are the main functions to be included. However, a JTAG interface implemented on the prototype allows in-system programming so that the equipment can be updated, and further signal processing algorithms can be included in the future, without changing the hardware.

\subsection{ECG data display and storage}

The ECG-IMT04 includes a $128 \times 64$ pixel resolution graphics displays the operation options (measure, store, transfer) and the ECG being recorded and/or monitored. The measured data can either be stored on a SD (secure digital) memory card or transferred to a host PC. The SD memory card and the graphics screen share the synchronization signal (UCLK) and the data output signal (SIMO). The second SPI communications port is used to transfer the data to a host computer a rate of 19200 baud through an RS-232 port if available. In order to maintain compatibility with current computer configurations and to save space in the PCB, the USB interface is fitted in the cable connector using a TUSB3410 RS232/IrDA Serial-toUSB Converter. 


\subsection{Patient safety considerations}

Before the ECG-ITM04 was tested on volunteers, it was necessary to measure the leakage current for different risk conditions. The equipment was considered safe if, at least, minimal NFPA 99 leakage current specifications are met as described in section 4.2. The ECG data acquisition system was connected to the AC adaptor and placed on a wooden table, 4 feet from the floor and at least 15 feet away from any other source of interference. For groundintact tests, the largest leakage current measured was $2.1 \mu \mathrm{A}$, between the reference electrode terminal and the mains ground. For ground-open tests the largest leakage current registered was $5.61 \mu \mathrm{A}$ between the reference electrode terminal and the mains ground. Both measurements are within the safety specification values $(10 \mu \mathrm{A}$ and $50 \mu \mathrm{A}$ respectively) and thus, pending corroboration from a certified laboratory, the equipment was considered safe.

\subsection{Experimental set-up}

Figure 10A shows the assembled ECG-ITM04. The ECG sample rate is adjusted to take 500 sps (samples per second) and thus a 1 GB SD card can hold over 7 days of uncompressed continuous recordings. The device was connected 5 volunteers to wear for a period of 24hours. Although the analog hardware includes two filter sections, including a $60 \mathrm{~Hz}$ notch filter, it is necessary to include a filtering operation in the microcontroller program.
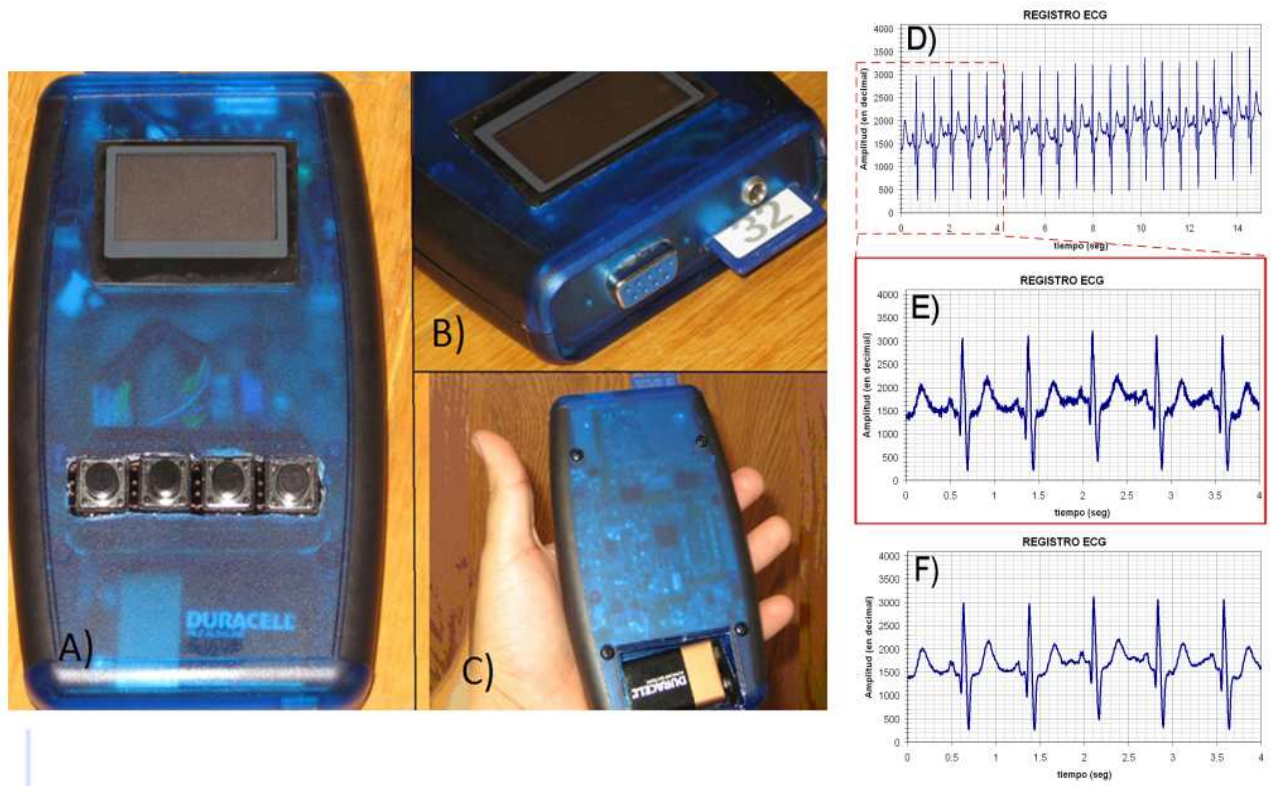

Fig. 10. A) Assembled ECG-ITM04, B) Serial port and SD card connections, C) Battery location. D) Typical EEG data exported into an Excel@ spreadsheet. E) Close-up of a 4.5 seconds record and F) filtered signal $(180 \mathrm{~Hz}$ cut off frequency). 


\subsection{Results and discussion}

Apart from the value that the ECG-ITM04 can have for diagnostic, it provides a unique opportunity to gather ECG information of the regional population for the purposes of statistical analysis and establishing public health policies. The value of an extensive database such as the MIT Arrhythmia Database has been widely recognized (Moody \& Mark, 2001) and helped in the development of automatic arrhythmia recognition software. Therefore the authors consider that distribution of the ECG-ITM04 amongst the regional public health clinics can be an important step towards developing an ECG database.

\section{Conclusions and future work}

The design of portable data acquisition systems is a multidisciplinary task that involves many areas of knowledge. It is important that the finished equipment includes all the necessary features to ensure easy operation. When it comes to biomedical equipment it is essential to ensure patient safety.

The proposed general data acquisition scheme can be used with minimal modifications to perform different biopotential measurements. For instance the EEG-ITM04 does not include the SD memory interface because the results are stored in the microcontroller main memory, reducing the power consumption and processor computational time to perform signal processing operations. In contrast, at present, The ECG-IMT04 requires a mass storage device to record the cardiac signals over a large period of time. Moreover, differences are filter cut frequency and sample rate. Fixed analogue filter cut-frequencies are implemented instead of gain-programmable filters to save power and printed circuit board space. The designs presented in this work perform according to the specifications stated by the end user. However, the availability of analogue front ends such as the ADS1298 from Texas Instruments and the ADuC842 from analog Devices, and powerful low-power consumption processing devices imply that that the design has to be updated continuously. Current work is dedicated to reduce power consumption and size of the measurement equipment, increase the number of analogue channels processing power as well as including wireless data transfer to ensure patient safety and, overall, produce more versatile instrumentation.

\section{Acknowledgements}

The authors acknowledge the financial support from CONACYT under grant FOMIX116062 that allowed the research to produce the EEG-ITM04. The authors also acknowledge the financial support from Dirección General de Educación SEP-DGEST) under grant 2317.09P that allowed the construction of the ECG-IMT04.

\section{References}

Abegunde D. O.; MathersC. D.; Adam T.; Ortegon M. \& Strong K. (2007). The burden and costs of chronic diseases in low-income and middle-income countries, The Lancet, Volume 370, Issue 9603, 8 December 2007-14 December 2007, pp. 1929-1938

Arden G. B. \& Constable P. A. (2006). The electro-oculogram, Progress in Retinal and Eye Research, Vol. 25, pp. 207-248 
Berbari E. J. (2000). Principles of Electrocardiography, In: The biomedical Engineering Handbook, Volume I, 2nd Edition, J. D. Bronzino (Ed.), pp. 231-240, Boca Raton: CRC Press LLC.

Bielecki I.; Świetliński J;. Zygan L. \& Horbulewicz A. (2004). Hearing assessment in infants from the hypoacusia risk group, Med Sci Monit, No. 10 (Suppl 2), pp. 115-117.

Bonfis P.; Uziel A. \& Pujol R. (1988). Screening for auditory dysfunction $\mathrm{n}$ infants by evoked otoacustic emission. Arch. Otolaryngol. Head Neck Surg, Vol. 114, pp. 887-90.

Cohen A. ( 2000). Biomedical Signals: Origin and Dynamic Characteristics; FrequencyDomain Analysis, In: The biomedical Engineering Handbook", Volume I, 2nd Edition, J. D. Bronzino (Ed.), pp. 951-974, Boca Raton: CRC Press LLC.

Cummins T. D.; Finnigan S. \& Ros J. (2007).Theta power is reduced in healthy cognitive aging, Int. J. Psychophysiol. Vol. 66, pp. 10-17

DeCharms R. C. (2007). Methods for Measurement and Analysis of Brain Activity. US Patent Applicacion. US 2007/0191704 A1.

Enderle J. (2000). Introduction to Biomedical Engineering. J Enderle (ED). pp. 549-626. San Diego, Calif.:Academic Press, 2000.

Fadem K. C. (2005). Evoked response testing system for neurological disorders. US Patent Application. US 11/570630.

Firoozabadi S. M. P.; Oskoei M. A. \& Hu H. (2008). A Human- Computer Interface based on Forehead Multi-channel Bio-signals to control a virtual wheelchair, In: Proceedings of the 14th Iranian Conference on Biomedical Engineering (ICBME), Shahed University, Iran, pp. 272-277, Feb. 2008

Givens G.; Balch D. C.; Murphy T.; Blanarovich A. \& Keller P. (2005). Systems, Methods and products For diagnostic Hearing Assesments Distributed Via the use of a Computer Network. US 6916291 B2.

Gutierrez Gnecchi J. A.; Doñan Ramirez R. \& Esquivel Gordillo C. F. (2009). Design and Construction of a Portable EEG for Auditory Evoked Potential Measurements, In: Electronics, Robotics and Automotive Mechanics Conference (cerma 2009), pp.457461

Handy T. C. (2004). Event-Related Potentials: A Methods Handbook, The MIT Press, Cambridge MA.

Henneberg K. A. (2000). Principles of Electromyography, In: The biomedical Engineering Handbook, Volume I, 2nd Edition, J. D. Bronzino (Ed.), pp. 242-251. Boca Raton: CRC Press LLC.

Instituto Nacional de Estadística, Geografía e Informática (INEGI). (2002). Estadísticas del Sector Salud y Seguridad Social. No.. 19, 2002. México, D.F., 2003. pp. 50-51.

Ivanov P. Ch. (2007). Scale-Invariant Aspects of Cardiac Dynamics Across Sleep Stages and Circadian Phases, IEEE Engineering in Medicine and Biology Magazine, Nov.Dec.2007, Vol. 26, Issue 6 , pp. $33-37$

Kligfield P.; Gettes L. S.; Bailey J. J.; Childers R.; Deal B. J. Hancock E. W.; van Herpen G.; Kors J. A. Macfarlane P.; Mirvis D. M. Pahlm O.; Rautaharju P.; \& Wagner G. S. (2007). Recommendations for the Standardization and Interpretation of the Electrocardiogram: Part I: The Electrocardiogram and Its Technology A Scientific Statement From the American Heart Association Electrocardiography and 
Arrhythmias Committee, Council on Clinical Cardiology; the American College of Cardiology Foundation; and the Heart Rhythm Society Endorsed by the International Society for Computerized Electrocardiology. Journal of the American College of Cardiology, Vol. 49, Issue 10, pp. 1109-1127.

Klimesch W.; Sauseng P.; Hanslmayr S.; Gruber W. \& Freunberger R. (2007). Event-related phase reorganization may explain evoked neural dynamics, Neurosci. Biobehav. Rev. Vol. 31, No. 7, pp. 1003-1016.

Köpke W. (2007). Device for Determining Acoustically Evoked Brainstem Potentials. US Patent. US 7197350 B2.

Lam B. S. C; Hu Y.; Lu W. W.; Luk K.; Chang C.; Qui W. \& Chan F. (2007). Multi-adaptive filtering technique for surface somatosensory evoked potentials processing, Med. Eng. Phys. Vol. 27, pp. 257-266, 2007.

Luck S. J. (2005). An Introduction to the event-related potential technique, pp. 27-33. The MIT Press, Cambridge MA. ISBN-10: 0-262-62196-7, ISBN-13: 978-0-262-62196-0

Maglogiannis I; Wallace M. \& Karpouzis K. (2007). Image, signal and distributed data processing for networks of eHealth applications, IEEE Engineering in Medicine and Biology Magazine, Sept. Oct. 2007, Vol. 26, No. 5, pp. 14-17

Masuda K.; Masuda T.; Sadoyama T.; Inaki M. \& Katsuta S. (1999). Changes in surface EMG parameters during static and dynamic fatiguing contractions, Journal of Electromyography and Kinesiology, Vol. 9, pp. 39-46.

Moody G. B. \& Mark R. G. The Impact of the MIT-BIH Arrhythmia Database, IEEE Engineering in Medicine and Biology Magazine, May June 2001, Vol. 20, Issue 3, pp. $45-50$.

Myers J. (2003). Exercise and Cardiovascular Health, Circulation 2003, Vol. 107, pp. e2-e5.

National Institute of Health: Early identification of Hearing impairment in infants and young children. (1993). NIH Consensus Statement, No. 11, pp. 1-24.

Preissl H.; LoweryC. L. \& Eswaran H. (2004). Fetal magnetoencephalography: current progress and trends, Exp. Neurol. Vol. 190, pp. 28-36

Rodríguez-Díaz J. A.; Chavarria-Contreras C. L. \& Montes de Oca Fernández E. (2001). Frecuencia De Defectos Auditivos En 16 Estados De México, Revista de la SMORL. Vol 46, No. 3, pp. 115-117

Rompelman O. \& Ros H. H. (1986). Coherent averaging technique: A tutorial review. Part 1: Noise reduction and the equivalent filter. Part 2: Trigger Jitter, overlapping responses and nonperiodic stimulation, J. Biomed. Eng., Vol. 8, pp 24-35.

Sajda P.; Müller K. R. \& and Shenoy K. V. (2008). From the Guest Editors. IEEE Signal Processing Magazine - Special Section - Brain Computer Interfaces. Vol 25, No. 1, Jan 2008, pp. 16-18.

Schaul N. (1998). The fundamental neural mechanisms of electroencephalography, Electroencephalography and clinical neurophysiology Vol. 106, pp. 101-107.

Vanhatalo S. \& Kaila K.(2006). Development of neonatal EEG activity from phenomenology to physiology. Semin. Fetal Neonatal. Med. Vol. 11, pp. 471-478.

Velázquez Monroy O.; Barinagarrementería Aldatz F.; Rubio Guerra A. F.; Verdejo J.; Méndez Bello M. A.; Violante R.; Pavía A.; Alvarado-Ruiz R. \& Lara Esqueda A. (2007). Morbilidad y mortalidad de la enfermedad isquémica corazón y 
cerebrovascular en México, Archivos de Cardiologiía de México. Vol. 77, No. 1, Enero-Marzo 2007. pp. 31-39.

White K. R.; Vohr B. R. \& Behrens T. R. (1993). Universal newborn hearing screening using transient evoked otoacustic emission: Results from the Rhode Island hearing assessment project, Sem Hear, Vol. 14, pp. 18-29. 


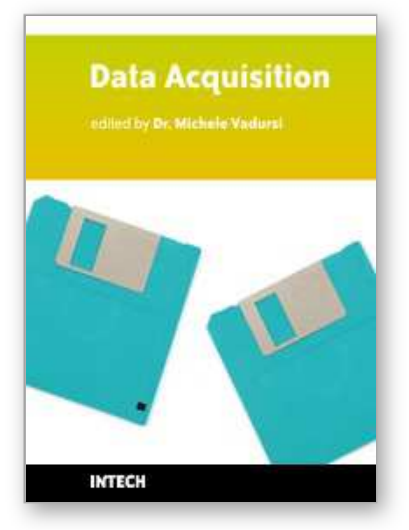

\author{
Data Acquisition \\ Edited by Michele Vadursi
}

ISBN 978-953-307-193-0

Hard cover, 344 pages

Publisher Sciyo

Published online 28, September, 2010

Published in print edition September, 2010

The book is intended to be a collection of contributions providing a birdâ€ ${ }^{\mathrm{TM}} \mathrm{s}$ eye view of some relevant multidisciplinary applications of data acquisition. While assuming that the reader is familiar with the basics of sampling theory and analog-to-digital conversion, the attention is focused on applied research and industrial applications of data acquisition. Even in the few cases when theoretical issues are investigated, the goal is making the theory comprehensible to a wide, application- oriented, audience.

\title{
How to reference
}

In order to correctly reference this scholarly work, feel free to copy and paste the following:

Jose Antonio Gutierrez Gnecchi, Daniel Lorias Espinoza and Victor Hugo Olivares Peregrino (2010). Microcontroller-based Biopotential Data Acquisition Systems: Practical Design Considerations, Data Acquisition, Michele Vadursi (Ed.), ISBN: 978-953-307-193-0, InTech, Available from:

http://www.intechopen.com/books/data-acquisition/microcontroller-based-biopotential-data-acquisitionsystems-practical-design-considerations

\section{INTECH}

open science | open minds

\section{InTech Europe}

University Campus STeP Ri

Slavka Krautzeka 83/A

51000 Rijeka, Croatia

Phone: +385 (51) 770447

Fax: +385 (51) 686166

www.intechopen.com

\section{InTech China}

Unit 405, Office Block, Hotel Equatorial Shanghai

No.65, Yan An Road (West), Shanghai, 200040, China

中国上海市延安西路65号上海国际贵都大饭店办公楼405单元

Phone: +86-21-62489820

Fax: $+86-21-62489821$ 
(C) 2010 The Author(s). Licensee IntechOpen. This chapter is distributed under the terms of the Creative Commons Attribution-NonCommercialShareAlike-3.0 License, which permits use, distribution and reproduction for non-commercial purposes, provided the original is properly cited and derivative works building on this content are distributed under the same license. 